\title{
An Analytical Study on the Correlation Between Alcohol Abuse and Domestic Violence: Focusing on Straus' Conflict Management Behavior
}

\author{
Misook Cho ${ }^{1}$ \\ ${ }^{1}$ Professor, Department of Social Welfare,Sahmyook University, South Korea, joms@syu.ac.kr
}

\begin{abstract}
This study viewed conflict management behavior as a process of changing conflict into controllable situations or facilitating conflict resolution and attempted to reveal the correlation between alcohol abuse and domestic violence through empirical research and seek changes in conflict management behavior through integrated interventions for these two issues. The main findings are as follows. First, $51.4 \%$ of violent offenders who committed at least one act of domestic violence in the past year were alcoholics. This proves that there is a close correlation between drinking and domestic violence. Second, among domestics violence offenders, there were significant differences between the alcoholic and non-alcoholic groups in terms of conflict management behaviors such as "throwing things" or "pushing hard" ( $\mathrm{p}=0.0001)$, "kicking and punching" $(\mathrm{p}=0.021)$, and "beating someone without mercy" ( $p=0.007)$. Third, among socioeconomic factors, there was a significant difference between the alcoholic and non-alcoholic groups in the "family-type" and "economic status" of domestic violence offenders. The following suggestions were made based on the results of the study. First, Intervention agencies should be capable of providing integrated services for alcohol abuse and domestic violence. Second, a continuous system establishment is required. Third, in terms of conflict management behavior, countermeasures, specific guidelines, and treatment support measures for alcohol and domestic violence should be legislated. Fourth, considering Korea's drinking cultural characteristics, the simultaneous incidence of drinking and domestic violence in conflict management behavior, demographic characteristics of domestic violence offenders with drinking problems, patterns of violence under the influence of alcohol.
\end{abstract}

Keywords: $\mathrm{CMB}$ (Conflict Management Behavior), Alcohol Abuse, Domestic Violence, Integrated Interventions

\section{Introduction}

Most patients treated for alcoholism have a history of experiencing violence such as abuse, beatings, and sexual violence. Brenda reported that childhood physical abuse experiences were highly correlated with drinking problems in a study on childhood abuse and alcohol problems[1]. Walker also found that the majority of murderers, robbers, and assaulters were drinkers in a study on the 'relationship between alcohol consumption and violence.' It was also reported that hostility increased according to alcohol consumption and led to expressing one's conflict through violent behavior based on Thematic Apperception Test (TAT) results[2]. According to a survey of 121 men who received counseling for domestic violence issues, $45.4 \%$ answered that drinking problems were the direct cause of domestic violence, and $44.6 \%$ said that they lost their ability to control anger. In particular, as a result of testing

Received: August 24, 2021; 1st Review Result: October 10, 2021; 2nd Review Result: November 25, 2021 Accepted: December 31, 2021 
the subjects for alcohol use disorder, $70.4 \%$ of the respondents were categorized under 'problematic drinkers,' and $24.6 \%$ were suspected to be alcohol dependent[3]. These results are about twice as high as when the same survey was conducted on the general public, indicating a high correlation between alcohol abuse and domestic violence.

The need for integrated interventions for these two issues is gaining momentum as a recent empirical study suggested that providing interventions for the drinking and violence problems of domestic violence offenders at the same time resulted in more positive therapeutic effects[4]. Although drinking does not always lead to violent behavior, there is a much higher risk of domestic violence. Even in other countries, drinking is related to more than $60 \%$ 80\% of domestic violence and assault cases. In particular, legal penalties for drinking were significantly higher in men, which is consistent with Smart's view that male alcoholism has a high prevalence of antisocial personality and causes more legal problems due to alcohol abuse[5].

Meanwhile, Straus[6] described that the basic premise of conflict management behavior is that conflict itself is not the cause of problems. Rather, problems are caused by adopting inappropriate and unsatisfactory methods to resolve conflicts. In particular, there is a general notion that drinking is a communal experience in Korea, and the context of its society's tolerance for drinking requires serious attention. Drinking not only increases violent behavior in families but also creates a vicious cycle of ceaseless alcoholism problems. Therefore, more systematic and empirical research is needed to analyze the relationship between drinking and domestic violence. The purpose of this study is to reveal the correlation between drinking and domestic violence through empirical research and discover integrated interventions to change conflict management behavior.

\section{Theoretical Framework}

\subsection{Domestic Violence}

In previous studies, the co-occurrence rate of drinking and domestic violence continues to be reported. There is found that $70 \%$ of the husbands of abused women were alcohol dependent, and reported that $92 \%$ of the perpetrators arrested for domestic violence used alcohol at the time of the violence[7]. In a domestic study, in a survey on wife abuse by the Korea Legal Aid Center for Family Relations, the husband's drinking habit was the number one cause of violence and It is reported that the higher the drinking level, the more severe the beatings of husbands against their wives[3]. Alcoholism causes psychological, behavioral, and social problems in the alcoholic himself and not only threatens his life, but also causes conflicts within the family and further threatens the mental health of family members. Children are the most directly and fatally affected by parental alcoholism.

In relation to this high co-occurrence of drinking and violence, in the West, recent empirical research results suggesting that the treatment effect is better if the domestic violence perpetrator's drinking and domestic violence problems are intervened at the same time support the need for an integrated intervention in both issues[8]. Meanwhile, there seems to be a lack of research and intervention efforts in Korea on the simultaneous occurrence of drinking problems and domestic violence, domestic violence perpetrators and victims with drinking problems, and domestic violence behaviors of alcoholics[8].

First of all, effective intervention should be based on empirical research, but the lack of existing domestic research and academic discussion on the interrelationship between drinking and domestic violence does not promote intervention in domestic violence behavior of domestic violence perpetrators and alcoholics with drinking problems. I think that was a factor. From the perspective of domestic violence perpetrators with drinking problems, unlike in the West, in Korea, the order time for domestic violence perpetrators is usually 50 hours, which is a very short period to have the effect of 
reducing violent behavior. In order to intervene not only in violent behavior but also in drinking problems within a short period of time, the limited time limit for the order will also act. It would be ideal to increase the time required for taking classes as a policy, but it seems difficult to expect improvement right away due to the opposition of the target audience and the lack of awareness of the relevant institutions[3].

Second, regarding the domestic violence behavior of alcoholics, experts from alcohol hospitals, general hospital psychiatrists, and community alcohol counseling centers have little interest in the domestic violence behavior of alcoholic clients, and even if the seriousness of the problem is revealed, drinking and family There are not many trained professionals who can intervene in both violence[7].

The victims of domestic violence may be trapped in domestically violent situations through isolation, power and control, traumatic bonding to the abuser, cultural acceptance, lack of financial resources, fear, and shame, or to protect children. In most of studies referred to the relationship between alcohol abuse and domestic violence as "a mutually reinforcing, disastrous cycle" and emphasized the need for effective intervention in both problems. Victims of domestic violence may experience severe psychological disorders, such as post-traumatic stress disorder (PTSD). Children who live in a household with domestic violence often show behavioral problems such as "internalizing problems" and 'externalizing problems from an early age, such as avoidance, hypervigilance to threats and dysregulated aggression, which may contribute to vicarious traumatization[7][8].

\subsection{Alcohol Use Disorder(AUD)}

Studies on the relationship between drinking and domestic violence suggested so far include direct cause/indirect cause model, Drunken-bum theory, disinhibition theory, peer support model coping mechanism hypothesis. The above various theories and hypotheses divide the relationship between drinking and domestic violence into two opposing views. In other words, it is argued that alcohol is a direct predictor of violence and that alcohol is an indirect predictor of violence rather than a direct cause[8].

There is disagreement on the definition of the word "alcoholism", it is not a recognized diagnostic governance. But Alcoholism is, broadly, any drinking of alcohol that results in significant mental or physical health problems [9]. Predominant diagnostic classifications are alcohol use disorder (DSM-5) or alcohol dependence (ICD-11); these are defined in their respective sources[10]. Studies suggesting that binge drinking directly increases the risk of violence by suppressing cognitive and perceptual abilities, or that chronic alcohol use causes or triggers organic brain damage associated with violent outbursts. This is supported by the result that excessive drinking remained a significant factor even when variables such as class, age, marital relationship type, education level, and economic status were controlled[10]. In the indirect causal model, on the other hand, perpetrators use alcohol to make excuses for previous violence or justify planned violence, or to use alcohol in conflict situations when other coping strategies are not learned. Although excessive drinking increases the risk of domestic violence, the above explanation is confirmed by the research results that the drinking problem becomes meaningless as it controls attitude variables such as men's disregard for women and control[11]. After a person stops drinking alcohol, they may experience a low level of withdrawal lasting for months. Questionnaires are usually used to detect possible Problem Drinking.

\subsection{Conflict Management Behavior(CMB)}

There are many different definitions of conflict, which is generally defined differently from psychological, political/social, and administrative perspectives.

Darling \& Walker[12] view conflict as a situation where an organization's decision-making or 
policy-making criteria are ambiguous, causing difficulties in choosing an alternative. Thomas \& Kilmann[13] define conflict as various forms of struggles over values or claims to values, authority, power, and scarce resources. In particular, Tuxedo[14] integrated the definitions of many scholars and presented the aspects of conflict as: 1) the state that precedes conflict such as the lack of resources or differences in policy values, 2) the emotional states of individuals involved in conflict situations such as stress, tension, hostility, and anxiety, 3) the individual's perception of conflict situations, and 4) conflict behavior. He also argued that conflicts go through five dynamic stages: "Latent conflict $\rightarrow$ perceived conflict $\rightarrow$ felt conflict $\rightarrow$ manifest conflict $\rightarrow$ conflict aftermath".

Until now, conflict has been perceived as negative, a matter that must be eliminated or resolved. However, conflict avoidance is changing into conflict management as the positive functional aspects of conflict can promote adjusting various interests. Therefore, this study defines "conflict management behavior as a process that reframes conflict into controllable situations or facilitating conflict resolution" and seeks integrated interventions for alcohol abuse and domestic violence.

\subsection{Alcohol and Violent Behavior}

People who engage in violent behavior due to alcohol are reported to lack the ability to cope with conflict under extreme stress. When they are put in a stressful situation, they drink alcohol and express their repressed anger and mixed feelings. They often end up in situations that they are not even aware of due to chronic habits that were developed throughout a persistent lifestyle. In particular, they usually cannot resolve their frustration and go into a rage after drinking. This behavior is followed by feelings of guilt from the abusive language, assault, and rampage after they sober up. If they have another opportunity to drink again, the vicious cycle of not being able to control conflict management behavior repeats, and the link between drinking and emotional outbursts redevelops to randomly release their emotions[15].

Livingston[15] described alcohol abuse and violent behavior as a "mutually reinforcing, disastrous cycle" and emphasized the need for integrated interventions for both problems. According to Kantor \& Strauss[16], research on the relationship between alcohol and violent behavior can be organized into five models: 1) the direct cause/indirect cause model, 2) the Drunken Bum model, 3) the disinhibition model, 4) the male peer support model, and 5) the coping mechanism model. These models divide the relationship between alcohol and domestic violence into two opposing views. One argues that alcohol is a direct predictor of domestic violence and the other asserts that drinking is an indirect predictor of domestic violence[17].

First, studies that consider alcohol as a direct cause explain that binge drinking directly increases the risk of violence by suppressing cognitive and perceptual abilities[18] and that chronic alcohol use causes or triggers organic brain damage associated with violent outbursts[19]. This view is supported by the results that excessive drinking remained a significant factor even when controlling variables such as class, age, marital status, level of education, and economic status. Studies supporting the indirect cause model argue that domestic violence offenders use alcohol to make excuses for past acts of violence or to justify planned violence[20], and use alcohol in conflict situations when other coping strategies are not learned[21].

In fact, husbands who engage in domestic violence show a significantly higher rate of unemployment and their violent behaviors are closely related to the amount of alcohol they drink.

Moreover, Gelles[22] reported that alcohol has an absolute correlation with domestic violence. These findings demonstrate the need to focus on treating alcoholism for violent men and nonviolent conflict management behavior for alcoholic men. 


\subsection{Management of Domestic Violence}

Combining previous studies, it can be seen that there is a correlation between alcohol consumption and domestic violence, but the causal relationship is not clear. However, the findings of the literature study have pointed out that domestic violence exists even by non-drinking husbands, and quitting alcohol does not mean that domestic violence is eradicated[23]. Therefore, in this study, based on the hypothesis that drinking is an indirect cause of domestic violence, regarding the relationship between drinking and domestic violence, It is important to intervene in both issues of drinking and violence for domestic violence perpetrators with drinking problems. Most domestic violence perpetrators participate in therapy against their will. They say that they denied, minimized, justified, or blamed outsiders for their violent behavior, beat their wives because they did something right, or used violence to change their habit[23].

In addition, since they express strong feelings of anger against the Domestic Violence Prevention Act itself and doubt the effectiveness of the program, therapists have considerable difficulties in forming relationships with them. It is common for people with drinking problems to show resistance at the treatment site because it is their characteristic to deny their drinking and the consequences of drinking. In the disease model that traditionally intervenes in alcohol abuse, alcohol abuse and dependence are viewed as a negative disease, so this characteristic becomes a real obstacle to recovery[23].

A perpetrator with a drinking problem, who has these two issues, blames his/her violent behavior for drinking and justifies the violence, so it is not easy to intervene in the violent behavior. In addition, it is not easy to intervene in drinking because he denies that his drinking problem is not too serious. This means that perpetrators with drinking problems have low motivation to change for both drinking and violence, and this characteristic acts as a significant obstacle to intervention. Motivation for change is a spontaneity to change a specific behavior, and when it is considered that the degree or level of change motivation is not fixed but variable over time and situation, Reducing the denial and resistance to alcohol and violent behavior displayed by the perpetrators and enhancing the motivation for change will be the key to maximizing the effectiveness of the therapy[23]. Therefore, the synchronization strategy for them is judged to be the most important factor to be considered in intervention.

Also, it is required to diversify the channels of counseling along with the expression of emotions through counseling. Furthermore, the problems of adaptation experienced by children from alcoholic families are closely related to family dynamics, and in particular, active interest in the family system and practical help are required[24]. Family counseling is required to learn open communication for functional family relationships and to prevent problems of excessive closeness between family members. In the case of children in adulthood, interpersonal relations programs that can resolve the problem of trust in interpersonal relationships and conflicts in the adaptation process that identify mothers and fathers are required and programs that can have a positive outlook.

This intervention is expected to be a preventative and intervention to prevent the various psychological problems that alcoholic children conflict with in the process of adaptation from being fixed as a problem of adaptation. Programme facilitators guide small group participants through a curriculum of adult education-style modules, which draw on a variety of therapeutic interventions, but predominantly cognitive behavioural therapy, family therapy approach and psycho-social intervention[24].

\section{Research Method}

This study was conducted by setting socioeconomic status as a control variable based on an analytical framework. Both alcoholic and non-alcoholic groups were set as independent variables and 
conflict management behavior was considered as a dependent variable. Also, the research focused on subjects who were court-ordered to take domestic violence classes. Straus'CTS (Conflict Tactics Scale) and NASTI (Alcoholism Screening Test of Seoul National Mental Hospital I) were used as measurement tools[6].

\subsection{CTS (Conflict Tactics Scale)}

The Conflict Tactics Scale (CTS) by Straus[6] was modified and supplemented to measure the dependent variable (conflict management behavior), focusing on physical violence. CTS is based on the premise that conflict itself does not cause problems but that they are caused by using inappropriate and unsatisfactory methods to resolve them. In this scale, conflict tactics consist of 18 items, including rational methods (3 items), verbal aggression (6 items), physical violence ( 8 items), and one other item. This study reconstructed the eight items corresponding to physically violent behavior into seven by integrating the 7th and 8th items, which do not fit the circumstances in Korea[25]. To measure violent behavior, the Conflict Tactics Scale (CTS) was used. The reliability reported at the time of the study of Straus was .83, and in this study, the scale used the reliability was .91.

\subsection{NAST I}

Most people who drink alcohol don't have Alcohol use disorder. Alcohol use screening tests are questionnaires designed to find out if you have alcohol use disorder(AUD). Alcohol use disorder is a pattern of excessive drinking that can cause serious problems in your work, relationships, and health. But if you have Alcohol use disorder, you may: First, Find it hard to control the amount of alcohol you drink, Second, Spend a lot of time thinking about drinking, Third, Need increasing amounts of alcohol to feel its effects[10].

But, NAST I (Alcoholism Screening Test of Seoul National Mental Hospital I) was used to screen alcoholism in this study. This scale was developed by Pokorny et al.[26] and consists of 12 items. Participants who answer 'yes' to four or more items fall under a risk group for alcoholism, and is the minimum level at which treatment for alcohol dependence is required.

\subsection{Sampling and Survey Method}

This study was based on the perspective of alcohol and domestic violence in conflict management behavior. Accordingly, it focused on subjects who have received community service orders at the S probation office due to domestic violence from February to June 2021. The total number of participants was 97, of which 46 were related to domestic violence, and 35 were involved in the final analysis, excluding cases with unclear or missing answers.

\section{Result Analysis}

Among the 35 domestic violence offenders who were the subjects of the final analysis, 18 (51.4\%) received a score of 4 or higher in NASTI, corresponding to alcoholism groups. As shown in the general characteristics of the subjects in [Table 1], the average age of the violent offenders was 46.8 years in the alcoholic group and 47.7 years in the non-alcoholic group, similar in both groups. Both groups also had similar educational and religious backgrounds. However, in terms of the family type of violent offenders, the alcoholic group showed a higher proportion of large or extended families than the non-alcoholic group, which was consistent with a study by Tolman \& Edleson[27]. The alcoholic group also had a lower economic status compared to the non-alcoholic group. The Wilcoxon test was 
conducted to investigate the differences between domestic violence and alcoholism in conflict management behavior. The results are as follows.

First, one in two violent offenders or $51.4 \%$ of violent offenders who committed at least one act of domestic violence in the past year were alcoholics. This proves that drinking and domestic violence are closely related.

Second, as shown in [Table 2], in terms of the conflict management behavior of domestic violence offenders, there was a very significant difference between alcoholic and non-alcoholic groups in "throwing things" or "pushing hard" ( $\mathrm{p}=0.0001)$, "kicking and punching" $(\mathrm{p}=0.021)$, and "beating someone without mercy" ( $\mathrm{p}=0.007)$.

[Table 1] Traits of Statistics

\begin{tabular}{|c|c|c|c|c|}
\hline Variable & Category & Alcoholic groups $\mathrm{N}(\%)$ & Non-alcoholic groups $\mathrm{N}(\%)$ & t or $x^{2}(p)$ \\
\hline Age & Average & 46.8 & 47.4 & $0.261(0.873)$ \\
\hline Family & $\begin{array}{l}\text { Nuclear } \\
\text { Large }\end{array}$ & $\begin{array}{c}14(77.78) \\
4(22.22)\end{array}$ & $\begin{array}{c}17(100.00) \\
0(0)\end{array}$ & 4. $265(0.038) *$ \\
\hline $\begin{array}{l}\text { School } \\
\text { career }\end{array}$ & $\begin{array}{c}\text { College } \\
\text { High school } \\
\text { Middle school }\end{array}$ & $\begin{array}{l}2(11.11) \\
9(50.00) \\
7(38.89)\end{array}$ & $\begin{array}{c}1(5.88) \\
10(58.82) \\
6(35.29) \\
\end{array}$ & $1.283(0.733)$ \\
\hline Religion & $\begin{array}{l}\text { Buddhism } \\
\text { Christian } \\
\text { Catholic } \\
\text { Others } \\
\text { Nothing }\end{array}$ & $\begin{array}{c}6(33.33) \\
3(16.67) \\
0(0) \\
0(0) \\
9(50.00)\end{array}$ & $\begin{array}{c}5(29.41) \\
1(5.88) \\
2(11.76) \\
0(0) \\
9(52.94)\end{array}$ & 3. $064(0.381)$ \\
\hline Economic & $\begin{array}{l}\text { High } \\
\text { Medium } \\
\text { Low }\end{array}$ & $\begin{array}{c}0(0) \\
5(27.78) \\
13(72.22)\end{array}$ & $\begin{array}{l}4(23.53) \\
8(47.06) \\
5(29.41)\end{array}$ & $8.226(0.016) *$ \\
\hline
\end{tabular}

$* \mathrm{p}<.05$

[Table 2] The Wilcoxon Test for CMB of Domestic Violence Offenders between Alcoholic and Nonalcoholic Groups

\begin{tabular}{|c|c|c|c|c|c|}
\hline СТВ & Groups & $\mathrm{N}$ & M & Statistic & $\mathrm{p}$ \\
\hline V1 (throwing things) & $\begin{array}{c}\text { Alcoholic } \\
\text { Non-alcoholic }\end{array}$ & $\begin{array}{l}18 \\
17\end{array}$ & $\begin{array}{l}3.33 \\
1.64\end{array}$ & 185.0 & $0.0001 * * *$ \\
\hline V2 ( pushing hard) & $\begin{array}{c}\text { Alcoholic } \\
\text { Non-alcoholic }\end{array}$ & $\begin{array}{l}18 \\
17\end{array}$ & $\begin{array}{c}3.5 \\
1.52 \\
\end{array}$ & 153.0 & $0.0001 * * *$ \\
\hline $\begin{array}{l}\mathrm{V} 3 \text { (slapping someone } \\
\text { in the face) }\end{array}$ & $\begin{array}{c}\text { Alcoholic } \\
\text { Non-alcoholic }\end{array}$ & $\begin{array}{l}18 \\
17\end{array}$ & $\begin{array}{l}2.22 \\
1.47\end{array}$ & 252.0 & 0.057 \\
\hline V4 (kicking \& punching) & $\begin{array}{c}\text { Alcoholic } \\
\text { Non-alcoholic }\end{array}$ & $\begin{array}{l}18 \\
17\end{array}$ & $\begin{array}{l}2.66 \\
1.76\end{array}$ & 239.5 & $0.021 *$ \\
\hline V5 (clubbing) & $\begin{array}{c}\text { Alcoholic } \\
\text { Non-alcoholic }\end{array}$ & $\begin{array}{l}18 \\
17\end{array}$ & $\begin{array}{l}1.94 \\
1.35\end{array}$ & 267.0 & 0.130 \\
\hline $\begin{array}{l}\text { V6 (beating someone } \\
\text { without mercy) }\end{array}$ & $\begin{array}{c}\text { Alcoholic } \\
\text { Non-alcoholic }\end{array}$ & $\begin{array}{l}18 \\
17 \\
\end{array}$ & $\begin{array}{l}2.33 \\
1.29\end{array}$ & 234.0 & $0.007 * *$ \\
\hline $\begin{array}{l}\text { V7 (threatening someone } \\
\text { with a weapon) }\end{array}$ & $\begin{array}{c}\text { Alcoholic } \\
\text { Non-alcoholic }\end{array}$ & $\begin{array}{l}18 \\
17\end{array}$ & $\begin{array}{l}1.61 \\
1.05\end{array}$ & 270.0 & 0.074 \\
\hline
\end{tabular}

Although it was not statistically significant, there was also a difference between the two groups in behaviors such as "slapping someone in the face" or "threatening someone with a weapon."

Third, among social-statistical factors, there was a significant difference between the alcoholic and non-alcoholic groups in the "family-type" and "economic status" of violent offenders. In particular, 
the alcoholic group showed a higher proportion of large or extended families than the non-alcoholic group, which was consistent with a study by Tolman \& Edleson[27]. The alcoholic group also had a lower economic status compared to the non-alcoholic group, indicating significant differences.

\section{Conclusion and Suggestions}

The following conclusion and suggestions were made based on the results of the study.

First, Intervention agencies should be capable of providing integrated services for alcohol abuse and domestic violence. Therefore, institutions or programs for training relevant experts should include integrated content of the two issues in their curriculum and training courses for domestic violence counselors. Second, a continuous system establishment is required. If experts suspect drinking problems in domestic violence cases, they should take an integrated approach in immediate evaluation and coping strategies. Infrastructure should also be established between related systems to break the link between alcohol and domestic violence. Third, in terms of conflict management behavior, countermeasures, specific guidelines, and treatment support measures for alcohol and domestic violence should be legislated. Fourth, Korea's drinking culture tends to encourage drinking and is permissive for drinking and alcohol-induced behaviors. Considering these cultural characteristics, the simultaneous incidence of drinking and domestic violence in conflict management behavior, demographic characteristics of domestic violence offenders with drinking problems, patterns of violence under the influence of alcohol, characteristics of sober batterers who use violence even when they are sober, and cultural beliefs about violent behavior after drinking may show differences from studies in other countries.

Generally, Some people with alcohol use disorder are able to change their behaviors to cut back on drinking. Other people will need to stop completely. This is known as abstinence. Depending on the severity of your disorder, your provider may recommend one or more of the following treatments:

Brief or long-term counseling from a mental health Social Worker who specializes in treating alcohol use disorder.

Support groups: There are many different approaches and formats to alcohol use disorder support groups. Talk with your provider to find a group and approach that's right for you. The perpetrator intervention agency should be able to provide integrated services for drinking and domestic violence issues. Clinicians are well aware that the perpetrator's drinking problem is serious through practical experience, but the reality is that they are not able to intervene in the perpetrator's drinking problem due to lack of knowledge about the relationship between drinking and domestic violence and lack of professional skills to deal with drinking problems. Therefore, it would be desirable to include content that deals with both issues in the curriculum and domestic violence counselor training course to foster experts who can intervene in drinking and domestic violence issues. In addition, experts working at alcohol treatment centers will need knowledge and training on domestic violence in order not to miss the domestic violence behavior of problem drinkers.

Medication-assisted treatment: Certain medications may reduce your cravings for alcohol. These medicines are only for people who have stopped or are trying to stop drinking altogether. Therefore, the following approach should be included in programs to increase the effectiveness of interventions for clients who have both drinking and domestic violence problems.

First, it is necessary to understand that alcohol does not directly cause domestic violence but can be one of the factors causing such problem. Second, a list of signs that indicate that domestic violence offenders may start drinking should be made. Third, the personal consequences when domestic violence offenders drink alcohol must be understood. Fourth, developing plans and support systems to stay sober and maintain a violence-free life as part of offenders' goal to curb domestic violence is necessary. 


\section{Acknowledgement}

This paper was supported by the Sahmyook University Research Fund in 2021.

\section{References}

[1] Lisa Shannon, TK Logan, Jennifer Cole, Robert Walker, An Examination of Women's Alcohol Use and Partner Victimization Experiences Among Women With Protective Orders, Substance Use \& Misuse, (2009), Vol.43, No.8-9, pp.1110-1128, DOI: https://doi.org/10.1080/10826080801918155

[2] Lenore E. A. Walker, The Battered Woman Syndrome, 4th Edition, Springer Publishing Company, pp.79-92, (2016), DOI: https://doi.org/10.1891/9780826170996

[3] Korea Legal Aid Center for Family Relations(KLCFR), 25th The symposium of Korea Legal Aid Center for Family Relations, Prodeedings of the 25th symposium of KLCFR, The Korean Society Of Family Law, pp.21-30, (2019), October 15-16, Seoul, Korea, DOI: https://doi.org/10.31998/ksfl.2019.33.2.534

[4] Juliana Carlson, Erin Casey, Jeffrey L. Edleson, Richard M. Tolman, Tova B. Walsh, Ericka Kimball, Strategies to Engage Men and Boys in Violence Prevention: A Global Organizational Perspective, Violence Against Women, (2015), Vol.21, No.11, pp.1406-1425, DOI: https://doi.org/10.1177/1077801215594888

[5] Reginald G. Smart, Female and Male Alcoholics in Treatment: Characteristics at Intake and Recovery Rates, British Journal of Addiction to Alcohol \& Other Drugs, (1979), Vol.74, No.3, pp.275-281, DOI: https://doi.org/10.1111/j.1360-0443.1979.tb01348.x

[6] M. A. Straus, R. J. Gelles, S. K. Stienmetz, Measuring intra-family Conflict and Violence, Behind Closed Doors, Routledge, pp.155-173, (2006), DOI: https://doi.org/10.4324/9781351298681-7

[7] Ronagh J. A. McQuigg, International human rights law and domestic violence: the effectiveness of international human rights law, Routledge, pp.13-27, (2011), DOI: https://doi.org/10.4324/9780203819289

[8] Claudia García-Moreno, Heidi Stöckl, Protection of sexual and reproductive health rights: addressing violence against women, International Journal of Gynecology \& Obstetrics, (2009), Vol.106, No.2, pp.144-147, DOI: https://doi.org/10.1016/j.ijgo.2009.03.053

[9] https://meshb.nlm.nih.gov, May 9 (2020)

[10] Diagnostic and Statistical Manual of Mental Disorders (DSM-5), American Psychiatric Association, pp.490-497, (2013), ISBN: 978-0-89042-554-1.

[11] G. Borges, C. L. Bagge, C. J. Cherpitel, K. R. Conner, R. Orozco, I. Rossow, A meta-analysis of acute use of alcohol and the risk of suicide attempt, Psychological Medicine, (2016), Vol.47, No.5, pp.949-957, DOI: https://doi.org/10.1017/s0033291716002841

[12] J. R. Darling, W. E. Walker, Effective Conflict Management: Use of the Behavioral Style Model, Leadership \& Organization Development Journal, (2001), Vol.22, No.5, pp.230-242, DOI: https://doi.org/10.1108/01437730110396375

[13] Andrea Cordell, Ian Thompson, Thomas-Kilman Conflict Mode Instrument, The Procurement Models Handbook, Routledge, pp.27-51, (2019), DOI: https://doi.org/10.4324/9781351239509-37

[14] Susan C. Jarboe, Hal R. Witteman, Intragroup Conflict Management Survey, PsycTESTS Dataset, (1996), DOI: https://doi.org/10.1037/t46356-000

[15] Ross Lee E., Measuring Domestic and Intimate Partner Violence, Domestic Violence and Criminal Justice, Routledge, pp.21-31, (2017) DOI: https://doi.org/10.4324/9781315157092-3

[16] G. K. Kantor, M. A. Strauss, The "Drunken Bum" Theory of Wife Beating, Physical Violence in American Families, Routledge, pp.213-230, (1990), DOI: https://doi.org/10.4324/9781315126401-15 
[17] M. Harway, J. O'Neil, What Causes Men to Be Violent against Women?: The Unanswered and Controversial Question, Book Context and Critiques of O'Neil and Harway's Multivariate Model Explaining Men's Violence against Women, Sage Publication, pp.209-246, (1999), DOI: https://doi.org/10.4135/9781452231921.n1_

[18] O. W. Barnett, R.W. Fagan, Alcohol use in male spouse abusers and their female partners, Journal of Family Violence, (1993), Vol.8, pp.1-25, (1993), DOI: https://doi.org/10.1007/bf00986990

[19] R. Caetano, J. Schafer, C. B. Cunradi, Alcohol-Related Intimate Partner Violence Among White, Black, and Hispanic Couples in the United States, Domestic Violence, Routledge, pp.153-160, (2007), DOI: https://doi.org/10.4324/9781315264905-11

[20] N. D. Chartas, J. R. Culbreth, Counselor Treatment of Coexisting Domestic Violence and Substance Abuse: A Qualitative Study, Journal of Addictions \& Offender Counseling, (2011), Vol.22, No.1, pp.2-11, DOI: https://doi.org/10.1002/j.2161-1874.2001.tb00156.x

[21] R. P. Maiden, Alcohol Dependence and Domestic Violence: Incidence and treatment implications, Alcoholism Treatment Quarterly, (1997), Vol.15, No.2, pp.31-50, DOI: https://doi.org/10.1300/J020v15n02_03

[22] Heather Douglas, Women, Intimate Partner Violence, and the Law, Oxford University Press, pp.120-149, (2021) DOI: https://doi.org/10.1093/oso/9780190071783.003.0006

[23] Tod Augusta-Scott, Preparing Men to Help the Women They Abused Achieve Just Outcomes: A Restorative Approach, Innovations in Interventions to Address Intimate Partner Violence, Routledge, pp.173-198, (2017), DOI: https://doi.org/10.4324/9781315532776-12.

[24] United Nations, Supplement to the Handbook for Legislation on Violence against Women, United Nations, pp.21-34, (2013), DOI: https://doi.org/10.18356/0bc1d11e-en

[25] Misook Cho, A Study on the Impact of Violent Behavior Awareness on Domestic Violence : Focusing on the Social Group Work Intervention Effect, Asia-pacific Journal of Convergent Research Interchange, (2020), Vol.6, No.8, pp.41-50, DOI: https://doi.org/10.47116/apjcri.2020.08.05

[26] Alex D. Pokorny, Byron A. Miller, Howard B. Kaplan, Brief Michigan Alcoholism Screening Test, PsycTESTS Dataset, (1972), DOI: https://doi.org/10.1037/t01548-000

[27] Richard M. Tolman, Tova Walsh, Engaging Men in Violence Prevention, Sourcebook on Violence Against Women, Sage Publications, pp.351-367, (2018), DOI: https://doi.org/10.4135/9781483399591.n16 